Original Research Paper

\title{
Peninjauan Dokumen Mutu Pascasarjana Unram untuk Menunjang Penguatan SPMI dan SPME
}

\author{
Joni Rokhmat ${ }^{1,2,4^{*}}$, Wildan ${ }^{1,2}$, Taslim Sjah' ${ }^{3}$, Ulpah $^{1}$, Lulu Il Muntaz ${ }^{1}$ \\ ${ }^{1}$ Department of Education Administration, Postgraduate Program, University of Mataram, Indonesia \\ ${ }^{2}$ Department of Science Education, Postgraduate Program, University of Mataram, Indonesia \\ ${ }^{3}$ Department of Dry Land Agriculture, Postgraduate Program, University of Mataram, Indonesia \\ ${ }^{4}$ Department of Physics Education, Teacher Training and Education Faculty, University of Mataram, Indonesia
}

https://doi.org/10.29303/jpmpi.v3i2.1219

Sitasi: Rokhmat, J., Wildan, Sjah, T., Ulpah \& Muntaz, L. I (2022). Peningkatan Profesionalisme Guru melalui Peneltian Tindakan Kelas. Jurnal Pengabdian Magister Pendidikan IPA, 5(1)

\author{
Article history \\ Received: 10 Noveber 2021 \\ Revised: 17 Desember 2021 \\ Accepted: 30 Desember 2021 \\ *Corresponding Author: Joni \\ Rokhmat, University of \\ Mataram, Mataram, Indonesia; \\ Email: joni.fkip@unram.ac.id.
}

\begin{abstract}
This electronic document is a "live" template. The various Abstract: Kualitas dokumen mutu merupakan unsur vital dalam penguatan sistem penjaminan mutu internal (SPMI) maupun eksternal (SPME). Tujuan pengabdian ini melakukan peninjauan dokumen mutu Pascasarjana Universitas Mataram meliputi dokumen kebijakan, manual, standar, dan formulism utu. Metode pelaksanaan mengadakan workshop pembahasan dokumen mutu dengan melibatkan pemangku kepentingan yang terdiri dari unsur pimpinan Pascasarjana Unram, beserta staf, program sudi di lingkungan Pascasarjana, Lembaga Penjaminan Mutu dan Pengembangan Pendidikan (LPMPP), serta berbagai lembaga eksternal Unram yang memiliki hubungan kerjasama dalam pengembangan pendidikan. Hasilnya menunjukkan bahwa dokumen mutu yang ada sekarang dengan penetapan tahun 2018 harus dilakukan perbaikan mencakup beberapa hal berikut: 1) perlu menambahkan standar pelampauan di luar delapan standar yang ditetapkan Dikti, 2) perlu menambahkan standar penyelenggarakan MBKM, serta 3) merevisi beberapa konten yang sudah ada seiring dengan dinamika pendidikan yang terus berkembang. Direkomendasikan agar segera dilakukan revisi dokumen mutu yang ada dengan memperhatikan berbagai masukan dari seluruh peserta workshop.
\end{abstract}

Keywords: Dokumen mutu, standar pelampauan SN-DIKTI, standar pelaksanaan MBKM, Pascasarjana Universitas Mataram

\section{Pendahuluan}

Pengabdian Kepada Masyarakat (PKM) termasuk salah satu unsur dari pelaksanaan Tri Dharma Perguruan Tinggi. Dalam KPM kali ini, kegiatan dilakukan dalam rangka mendukung upaya peningkatan sistem penjaminan mutu internal (SPMI) maupun eksternal (SPME). Sistem Penjaminan Mutu Internal (SPMI) menjadi basis terselenggaranya pendidikan yang berkualitas sementara Sistem Penjaminan Mutu Eksternal (SPME) diperlukan untuk memperoleh pengakuan dari pihak luar terkait dengan tingkat kualitas penyelenggaraan pendidikan, khususnya di Pascasarjana Unram.

Di Pascasarjana Unram, dokumen mutu yang terdiri dari kebijakan, manual, standar, dan formulir SPMI yang ada adalah ditetapkan pada tahun 2018. Hal ini kurang mendukung penguatan SPMI itu sendiri dan SPME, terutama dalam menunjang upaya reakreditasi menuju peringkat unggul. Secara ideal, dokumen mutu ini ditinjau dan disempurnakan secara berkesinambungan, minilam secara annual sehingga selalu sejalan dengan perkembangan pendidikan terkini. Saat ini, 
khususnya berkenaan dengan era industri 4.0 yang beberapa tahun kemudian dimungkinkan segera menuju era industri 5.0.

Dalam kegiatan akreditasi, SPMI tidak secara eksplisit mundul dalam setiap kriteria tetapi secara implisit SPMI ini menunjang kualitas dari setiap kriteria. Jadi, SMPI secara langsung menjadi keharusan selalu di-upgrade agar senantiasa sesuai dengan perkembangan pendidikan terkini.

Berdasarkan hasil studi awal, melalui interaksi informal tim pengabdian dengan penyelenggara program studi di lingkungan Pascasarjana Unram maupun melalui kegiatan lain yang kebetulan dilaksanakan di program studi mitra, diperoleh informasi bahwa peninjauan dokumen mutu belum dilaksanakan secara berkala dengan jangka waktu yang relatif cukup pendek. Idealnya, peninjauan ini dilakukan secara annual dengan mendasarkan berbagai keterbatasan atau kelemahan yang mungkin muncul dalam malakukan peninjauan dan penyempurnaan.

Sesuai dengan dua paparan di atas, maka dalam kegiatan pengabdian ini dirumuskan dua masalah pengabdian sebagai berikut: 1 . Bagaiman strategi penijauan dokumen mutu yang efektif dengan melibatkan seluruh stakeholder? 2. Bagaimana strategi mengimplementasikan SPMI dalam penyelenggaraan pendidikan?

Tujuan pengabdian pada masyarakat ini adalah: 1) Pengkajian dokumen mutu, mencakup kebijakan, manual, standar, dan formulir SPMI di Pascasarjana Unram. 2) Menyempurnakan dokumen mutu berdasar hasil kajian. 3) Menetapkan dokumen mutu sehingga menjadi dokumen legal sebagai landasan normatif penyelenggaraan pendidikan di lingkungan Pascasarjana Unram. Kegiatan pengabdian ini diharapkan dapat memberikan manfaat, bagi program studi di lingkungan Pascasarjana Universitas Mataram: 1) Penyempurnaan dokumen mutu untuk keperluan penyelenggaraan kegiatan Tri Dharma Perguruan Tinggi. 2) Mendukung program studi untuk penyediaan dokumen mutu yang terbaru dalam kegiatan akreditasi, dan 3) Sebagai penunjang terwujudnya penyelenggaraan pendidikan pascasarjana yang bermutu sesuai dengan standar-standar yang telah ditentukan.

\section{Metode}

\section{Tahapan Pemecahan Masalah}

Untuk memecahkan masalah di atas perlu diadakan pengabdian kepada Pascasarjana Unram tentang analisis dan pembahasan dokumen mutu yang mencakup dokumen kebijakan, manual, standar, dan formulir mutu. Dalan pengabdian ini diawali dengan analisis dokumen oleh tim pengabdian kemudian dilanjutkan dengan kegiatan workshop pembahasan dokumen mutu dengan mengundang pemangku kepentingan internal maupun eksternal, serta identifikasi rekomendasirekomendasi esensial untuk penyempurnaannya, dan terakhir dilakukan evaluasi hasil kegiatan.

Secara kerangka pengabdian adalah sebagai berikut: 1) Kondisi awal, Dokumen mutu dibuat dan ditetapkan tahun 2018, Kegiatan, Dilakukan kajian dokumen mutu Pascasarjana Unram, Diharapkan, Tim pengabdian memiliki rencana kegiatan analisis dan pembahasan, serta pembaruan penetapan dokumen mutu, 2) Kondisi awal, Tim Pengabdian belum memiliki pemahaman optimal pengembangan dokumen mutu Pascasarjana, Kegiatan, Menyelenggarakan workshop untuk menganalisis dan membahas karakteristik dokumen mutu yang sesuai dengan perkembangan pendidikan terkini, Kondisi diharapkan, Melalui workshop didapat kerangka konseptual pengembangan dokumen mutu yang relevan dengan perkembangan pendidikan terkini; 3) Kondisi awal, Tim Pengabdian belum pernah mengembangkan dokumen mutu sesuai dengan kondisi, Kegiatan, Penyusunan draf dokumen mutu Pascasarjana yang terdiri dari dokumen kebijakan, Diharapkan, Tersusun draf dokumen kebijakan, manual, standar, dan formulir mutu Pascasarjana.

\section{Khalayak Sasaran Antara yang Strategis}

Kegiatan pengabdian pada masyarakat ini melibatkan beberapa anggota pengelola Gugus Penjaminan Mutu Pascasarjana Unram yang beberapa di antaranya juga menjadi penyelenggara program studi di lingkungan Pascasarjana Unram. Adapun yang menjadi sasaran kegiatan pengabdian adalah dokumen mutu Pascasarjana Unram 


\section{Kriteria Kegiatan}

Dilematika peningkatan kualitas dokumen mutu sudah menjadi keniscayaan tidak hanya dipikirkan oleh pihak penyelenggara pascasarjana melalui gugus penjaminan mutu, tetapi juga menjadi permasalahan semua unsur yang terkait yang mencakup seluruh pemangku kepentingan internal dan eksternal. Pemangku kepentingan internal terdiri dari seluruh personal penyelenggara pascasarjana Unram, gugus penjaminan mutu, dan program studi di lingkungan pascasarjana. Pemangku kepentingan eksternal terdiri dari unsur lembaga atau unit yang secara langsung maupun tidak langsung memiliki hubungan kerjasama secara formal maupun non-formal. Hubungan kerjasama tersebut meliputi pemberdayaan sumberdaya bersama, serta pemanfaatan lembaga atau unit sebagai tempat pengembangan pengetahuan dan keprofesian, serta tempat kegiatan pendidikan dan latihan guna menunjang tercapainya kompetensi yang ditargetkan

\section{Metode Kegiatan}

Pengabdian ini menggunakan metode analisis dokumen, FGD internal tim pengabdian, dan workshop, serta proses penyusunan draf kerangka konseptual penyempurnaan dokumen mutu Pascasarjana Unram sesuai dengan perkembangan pendidikan terkini.

\section{Evaluasi}

Evaluasi ditujukan untuk memanfaatkan informasi yang diperoleh sebagai acuan dalam menentukan kegiatan selanjutnya. Evaluasi ini direncanakan dilakukan pada bagian proses pelaksanaan dan bagian akhir kegiatan dengan cara mengidentifikasi respon peserta workshop penyusunan dokumen mutu. Evaluasi tentang respon workshop tersebut dijaring melalui pembahasan melalui komunikasi dua arah.

\section{Hasil dan Pembahasan}

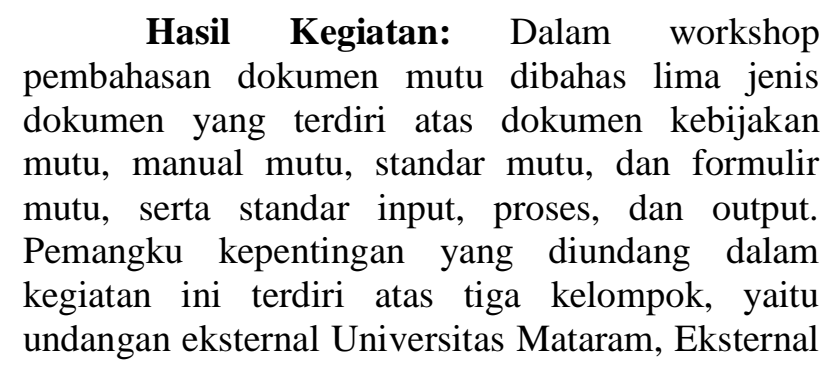

Pascasarjana dalam lingkungan Universitas Mataram, serta internal Pascasarjana Universitas Mataram.

Undangan di luar Universitas Mataram terdiri dari 19 undangan, yaitu 1) Dinas Pertanian Kabupaten Lombok Barat, 2) BMKG Provinsi Nusa Tenggara Barat, 3) BMKG Kabupaten Lombok Barat, 4) Dinas Lingkungan Hidup dan Kehutanan Provinsi Nusa Tenggara Barat, 5) SMKPP, 6) Dinas Pendidikan dan Kebudayaan Mataram, 7) LPMP Provinsi Nusa Tenggara Barat, 8) BKD Provinsi Nusa Tenggara Barat, 9) UNDIKMA Mataram, 10) Universitas Hamzanwadi, 11) SMAN 3 Mataram, 12) SMAK Kesuma Mataram, 13) SMKN 3 Mataram, 14) SMPN 2 Mataram, 15) SMPN 10 Mataram, 16) SMKN 1 Mataram, 17) Dinas Pendidikan dan Kebudayaan Provinsi Nusa Tenggara Barat, 18) Dinas Pertanian dan Perkebunan (Distanbun) Provinsi Nusa Tenggara Barat, serta 19) Dinas Pariwisata Provinsi Nusa Tenggara Barat.

Undangan di luar Pascasarjana di lingkungan Universitas Mataram adalah Ketua dan Sekretaris Lembaga Penjaminan Mutu dan Pengembangan Pendidikan (LPMPP) Universitas Mataram. Kelompok ketiga adalah undangan internal Pascasarjana yang terdiri atas Direktur dan Wakil Direktur, Ketua dan Sekretaris Program Studi Magister Administrasi Pendidikan, Magister Pertanian Lahan Kering, dan Magister Pendidikan IPA, serta seluruh pengelola Gugus Penjaminan Mutu (GPM) Pascasarjana Universitas Mataram.

Metode workshop yang digunakan adalah diawali 1) pemberian dokumen mutu kepada setiap undangan beberapa hari menjelang kegiatan, 2) sambutan Direktur Pascasarjana dan Ketua LPPM, 3) presentasi umum tentang gambaran isi setiap dokumen mutu, dan diakhiri dengan sesi 4) diskusi atau tanya jawab. Tahap ketiga dan keempat dibagi dalam dua sesi, sesi pagi dan sesi siang. Pada sesi pagi dokumen yang dibahas adalah kebijakan mutu, manual mutu, dan standar input-proses-output. Sementara, pada sesi siang dokumen yang dibahas adalah dokumen standar mutu dan formulir mutu.

Pembahasan dokumen mutu yang terdiri atas dokumen kebijakan, manual, standar, dan formulir mutu dikuti 19 peserta undangan dari luar Universitas Mataram, tiga undangan dari LPMPP, serta peserta internal dari Pascasarjana yang tergabung dalam Gugus Penjaminan Mutu sebanyak 17 orang sehingga total undangan ada 39 
orang. Dari 39 orang tersebut tercatat ada 13 kelompok masukan secara langsung dalam acara diskusi yang dilaksanakan secara online menggunakan media zoom dan satu kelompok masukan secara tidak langsung dengan cara mengirimkan via media whatsapp sehingga secara keseluruhan ada 14 kelompok masukan (Tabel 4.1).

Hasilnya dapat dirangkum sebagai berikut: Pertama, disarankan memasukkan aspek Merdeka Belajar Kampus Merdeka (MBKM) kedalam dokumen kebijakan (P-1). Selanjutnya, kedua disarankan agar dalam standar mutu, selain 24 standar yang terbagi pada standar pendidikan (8 standar), standar penelitian (8 standar), dan standar pengabdian (8 standar) sebaiknya dibuat standar pelampauan dengan jumlah sesuai kebutuhan (P-1, P-2, P-5, \& P-14). Ketiga, dalam dokumen kebijakan mutu perlu menambahkan pembelajaran berbasis kasus, pembelajaran berbasis proyek, dan implementasi kurikulum berbasis OBE, serta sistem pembelajaran daring dan blended (P-2, P-5).

Keempat, pada dokumen kebijakan, misi nomor 4 perlu ditambahkan aspek transparansi dan akuntabel, di beberapa halaman, seperti halaman 16, 17 perlu direvisi tata tulisnya. Hal penting lainnya yang perlu ditambahkan adalah "kebijakan kampus merdeka" (P-3). Selanjutnya, tujuan, khususnya aspek "pihak lain" perlu disebutkan secara operasional. Perlu ditinjau ulang struktur organisasi, tupoksi, serta standar isi SPMI (P-4). Standar-standar dan kurikulum supaya di-inline-kan dengan SPMI, formulis supaya dilengkapi, kaitkan dengan variabilitas setiap program studi, perlu ditinjau ulang manual mutu pada halaman 16 tentang diagram alir (P-5). Dari aspek tatakelola, OTK statute penyelenggaraan pendidikan pascasarjana masih di bawah PPS, untuk persyaratan ujian S2 dan S3 masih di bawah PPs (P-5b).

Untuk standar mutu, dapat diperhatikan hal-hal berikut: dibuatkan tabel sebagai fungsi dari IKU, kompetensi KKNI secara spesifik di program studi. Visi dan misi pascasarjana harus terkait dengan visi dan misi universitas dan program studi (P-6, P-8). Perlu ditinjau apakah SKL sudah berbasis OBE, dan standar (3) tentang sistem rekrutmen perlu dibuat lebih praktis, KKNI level berapa? (P-6) masih tentang SKL, P-7 menyarankan supaya dipertajam, misal pengusaha, anggota DPR, dosen, birokrat. Apa standar untuk lulusan bermutu (P-8).
Masukan lainnya, mempertanyakan bentuk PKM untuk mahasiwa pascasarjana karena ini biasanya diberlakukan untuk mahasiswa S2. Seharusnya tidak lagi menggunakan BNSP karena sekarang yang digunakan adalah SNPT, serta perlu singkronisasi visi unram dengan lembaga lain, seperti TOEFL( P-9). TOEFL perlu dibuat lebih luwes karena tidak memiliki makna untuk pengembangan profesi lulusan. Hal yang terjadi

TOEFL menjadi hal yang menakutkan bagi calon pendaftar (input). Selain itu, perlu ada nomenkelatur khusu untuk mahasiswa luar negeri dan ini dimasukkan kedalam standar input (P13). Penambahan oleh P-11 (sama dengan P-1) perlu penyesuaian standar mutu dengan kebijakan baru menteri, OBE, dan standar pelampauan, IKU + IK tambahan yang akan mendukung penyusunan LED.

Terakhir, P-14 secara khusus mengirimkan lembar masukan yang jika dirangkum dapat ditafsirkan berisi masukan berikut: 1) Dalam kesatuan entitas mutu seharusnya dokumen mutu pascasarjana linier dengan universitas; 2) Paparan dokumen mutu mencerminkan sistem penjaminan mutu yang masih bersifat permulaan; 3) Sistem mutu yang baik harus aplicated, 4) Terkait visi dan misi berdaya saing internasional, standar yang digunakan harus KKNI + pelampauan yang sepadan; 5) Pembahasan konseptual (teori) dan kerja laboratorium usahakan dalam urutan waktu sekuensial agar berpotensi menghasilkan keterampilan yang maksimal; 6) Kerja praktek di dunia nyata sebaiknya mendapatkan porsi yang cukup signifikan agar lulusannya memiliki kesiapan di dunia kerja; 7) Perlu pemutahiran sarana yang digunakan dalam pembelajaran sehingga kalau masih tertinggal, setidaknya tertinggalnya tidak terlalu jauh dari sarana yang ada di dunia kerja sehingga pengetahuan dan keterampilan penggunaan sarana dalam proses pembelajaran sejalan dengan pengetahuan dan keterampilan yang diperlukan di dunia kerja.

\section{Kesimpulan}

Dokumen mutu yang terdiri dari dokumen kebijakan, manual, standar, dan formulir mutu yang dimiliki Pascasarjana Universitas Mataram saat ini dengan penetapan bulan Desember tahun 2018 perlu direvisi dan disesuaikan dengan kebijakan baru Menteri Pendidikan, Kebudayaan, Riset, dan Teknologi. Selain itu perlu juga penyesuaian 
dengan kondisi sekarang dan kondisi kedepan yang berpotensi terus akan berkembang, khususnya juga dikaitkan dengan era sekarang, industri 4.0 dan persiapan menuju era industri 5.0.

Berdasar masukan dari peserta workshop, revisi dan singkronisasi atau penyesuaian yang perlu dilakukan antara lain: 1) penambahan standar pelampauan dari 24 standar yang telah ditetapkan dalam SN-DIKTI (permendikbud nomor 3 tahun 2020), serta yang telah dirumuskan dalam KKNI (perpres nomor 8 tahun 2012), 2) penambahan kebijakan terkait dengan kebijakan Merdeka Belajar Kampus Merdeka (MBKM), sistem pembelajaran daring, sistem pembelajaran blended, penerapan pembelajaran berbasis kasus, penerapan pembelajaran berbasis proyek, serta implementasi Outcome Based Education (OBE), 3) penetapan kembali standar input, standar proses, dan standar output, 4) perlu peninjauan urgensi penggunaan standar TOEFL, khususnya dikaitkan dengan relevansinya terhadap pengembangan keprofesian lulusan.

\section{Ucapan Terima Kasih}

Penulis mengucapkan terima kasih kepada Kementerian Pendidikan, Kebudayaan, ristek dan Pendidikan Tinggi, yang melalui Pascasarjana Universitas Mataram dan Lembaga Penelitian dan Pengabdian Masyarakat (LPPM) telah memberi dukungan financial terhadap pengabdian ini. Ucapan terima kasih juta disampaikan kepada para LPMPP yang telah bersedia menukung kegiatan ini dan pemangku kepentingan lainnya yang telah berpartisipasi sebagai peserta dalam kegiatan pengabdian ini

\section{Daftar Pustaka}

Husein, M. F., 2021. PENTINGNYA OUTCOME BASED EDUCATION DALAM AKREDITASII SERTIFIKASI INTERNASIONAL. PPT presentasi sosialisasi akreditasi/sertifikasi AUNQA.

No name, 2021. Outcome Based Education System. Diakses tanggal 30 April 2021 melalui URL:

https://www.bing.com/search?q=outcome + based+education+obe \&cvid $=2 \mathrm{a} 5 \mathrm{~d} 477 \mathrm{a} 4$ $\underline{6 e 14252 \mathrm{~b} 6 \mathrm{e} 462 \mathrm{~d} 1268 \mathrm{f} 2 \mathrm{fe} 2 \& \mathrm{aqs}=e d g e .1 .}$.

\subsection{6j0j4\&FORM=ANAB01\&PC $=$ $\underline{\mathrm{U} 531}$}

Sasongko, Dwiwahju, 2019. Akreditasi Program Studi, Pedoman Penilaian. Jakarta: BAN-PT, Majelis Akreditasi

Sunarpi, 2016. Rencana Induk Penelitian (RIP) Universitas Mataram Tahun 2016-2020. Mataram: Unram Press. 